\title{
Herpes simplex virus 1 infection upregulates stress protein expression in cultured retinal neurons
}

\author{
Peter G E Kennedy, Masato Wakakura, Wallace S Foulds, Geoffrey B Clements
}

\begin{abstract}
The production of a $57 \mathrm{~K}$ stress protein (StrP) after herpes simplex virus type 1 (HSV-1) infection was examined in cultured neonatal rat retinal cells. StrP expression in individual cells was identified using a monoclonal antibody, TI56. Indirect immunofluorescence of uninfected retinal cultures showed that approximately $40 \%$ of cells expressed neurofilament $\left(\mathrm{NF}^{+}\right)$and $5 \%$ expressed a low level of StrP. Following HSV infection the proportion of $\mathrm{NF}^{+}$cells decreased while the proportion of StrP positive cells became greater and the intensity of staining increased. The number of cells labelled with a polyclonal anti-HSV antibody increased with time after infection. Retinal neurons in culture can be infected with HSV, after which StrP expression is significantly upregulated.
\end{abstract}

A number of heat shock or stress proteins $(\mathrm{StrP})$ are induced in cells following a variety of noxious stimuli including elevated temperature, viral infection and toxic agents. ${ }^{12}$ StrP are ubiquitous, have been identified in a wide range of organisms and have been studied extensively. Studies of StrP induction in the nervous system ${ }^{34}$ and in the retina ${ }^{56}$ have, however, been limited. Following herpes simplex virus (HSV) infection of a variety of cell types, including those of the central nervous system, StrP expression is enhanced. It is possible that cell-encoded proteins, including StrP, may play a role in the regulation of both lytic and latent virus infections. For example, in primary cultures of human neurectodermal cells a $57 \mathrm{~K}$ StrP is induced in neurons and astrocytes after HSV infection. ${ }^{4}$ In addition the production of StrP defined by three monoclonal antibodies was recently demonstrated in cultured Muller cells following HSV infection but these cultures did not contain neurons. ${ }^{6}$ In vivo studies in rabbits have shown that a $74 \mathrm{~K}$ StrP was transported from the retina into the optic nerve. ${ }^{7}$ However, this does not necessarily imply that the StrP was induced in retinal ganglion cells, since StrP may be transferred from glia to the axon. ${ }^{8}$ In view of the possible involvement of StrP in the pathogenesis of herpes virus induced retinal diseases such as acute retinal necrosis ${ }^{9}$ and retinitis, ${ }^{210}$ it is important to identify unequivocally the retinal cell types in which StrP are constitutively expressed and those in which they are upregulated during viral infection. We have util- ised a method of obtaining retinal cell cultures containing a high proportion of neurons and report the upregulation of a 57K StrP in these cells following infection with HSV-1, thus extending significantly our previous studies. ${ }^{46}$

\section{Methods}

The culture of retinal neurons has been described in detail elsewhere. ${ }^{11-14}$ In brief, retinas were obtained from ether anaesthetised neonatal rats (age 1-5 days), collected in $0.25 \%$ trypsin in phosphate buffered saline (TPBS) and incubated at $36.5^{\circ} \mathrm{C}$ for $5-10$ mins. Single cells were obtained by repetitive trituration and the single cell suspension was pelleted by centrifugation (1000 rpm for 5 mins). The TPBS was replaced by Glasgow minimum essential medium (GMEM) supplemented with $10 \%$ fetal calf serum, $2 \mathrm{mM}$ L-glutamine and $1 \%$ antibiotic-antimycotic solution $(10,000$ unit penicillin, $10,000 \mathrm{mg}$ streptomycin and $25 \mathrm{mg}$ fungizone, Gibco). Dissociated cells were then dispersed onto either a monolayer of rabbit Muller cells precultured on $13 \mathrm{~mm}$ glass coverslips ${ }^{615}$ or laminin (10 ug/ $\mathrm{ml}$ ) precoated coverslips in each well of a Linbro multiwell plate (Flow) and incubated in $5 \% \mathrm{CO}_{2}$ in air at $36.5^{\circ} \mathrm{C}$. Cells from one retina were dispersed over 6-8 coverslips. The cultures were used after 2-5 days of primary culture in this study.

A monoclonal antibody (TI56) ${ }^{16}$ directed against a 57K StrP was used undiluted. Lytic HSV infection of human embryonic fibroblasts, baby hamster kidney $\mathrm{BHK} 21 / \mathrm{C} 13$ (BHK) cells and human neuronal cells ${ }^{4}$ results in the accumulation of a $57 \mathrm{~K}$ StrP identified by TI56. A monoclonal antineurofilament polypeptide antibody ${ }^{17}$ was used at a dilution of 1:100. Rabbit HSV antiserum (1:50) raised against whole virus was used. A polyclonal anti-glial fibrillary acidic protein (GFAP) antibody (Dako) was used at a dilution of 1:60. Antibody binding was visualised with fluorescein-conjugated anti-mouse (Miles-Yeda) or rhodamine-conjugated anti-rabbit (Nordic) Ig, both used at a dilution of $1: 30$.

The cells were infected with wild type (nonsyncytical plaque morphology, $t s^{+} s y n^{+}$) HSV1 Glasgow strain 17 at a multiplicity of infection (MOI) of usually 1 plaque forming unit (pfu) per cell as described in detail previously. ${ }^{4618}$ In a few experiments a MOI of 10 was used. Virus absorption was at $37^{\circ} \mathrm{C}$ for one hour. The cells were then washed and refed with GMEM and incubated at $37^{\circ} \mathrm{C}$ in $5 \% \mathrm{CO}_{2}$ 
Figure 1 Immunofluorescence of neonatal rat retinal culture stained for antineurofilament polypeptides.

Magnification $\times 900$.

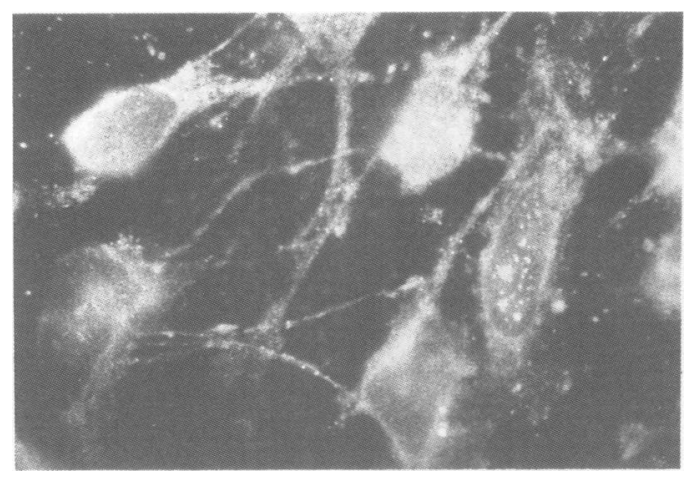

in air. HSV-infected BHK cells were used as positive controls as previously described. ${ }^{18}$

At six, 24 and 48 hours after virus absorption, cells were fixed in acetone at $-20^{\circ} \mathrm{C}$ for 10 minutes and stained using an indirect immunofluorescence procedure as reported previously. ${ }^{46}$ The stained cells were examined with a Leitz Ortholux fluorescence microscope. Double-labelling experiments in which cells were incubated with both NF and HSV antibodies simultaneously were also performed as previously reported. ${ }^{18}$ Double-labelling experiments using NF and TI56 antibody were not performed since both were mouse antibodies and both bound to intracellular structures, and therefore could not be distinguished in a given cell preparation. In control experiments, normal mouse ascitic fluid (undiluted) and normal rabbit serum (1:50) were used instead of the primary antibody. Uninfected and infected BHK cells were also used in further control experiments. In all experiments at least 150 cells in five randomly selected fields were counted per coverslip. A total of five independent experiments was performed in retinal cultures (laminin coated, with TI56 labelling in four and NF labelling in five) and a total of three independent experiments was carried out in co-cultures (with TI56 labelling in three and NF labelling in two). For technical reasons, for example, loss of cells or unsatisfactory staining, the antibody staining results were not given on each occasion for every time point.

\section{Results}

The cultured neuronal cell bodies were oval in shape, uniform in size (diameter approximately 15-30 $\mu \mathrm{m}$ ) and possessed distinctive neurites. They could be differentiated easily from glia on the basis of their size, shape and staining characteristics. Neurite outgrowth was prominent by 24 hours after establishment of the primary culture and in many cells the neurite length reached was greater than $50 \mu \mathrm{m}$ by 96 hours. Preparations co-cultured with the Muller cells had longer, thicker neurites and a higher proportion of cells with neurites than cultures on the laminin substrate. There were $55 \% \mathrm{NF}^{+}$(neurofilament positive) cells when co-cultured with Muller cells but only about $24 \%$ in the cultures grown on the laminin substrate (fig 1). Cells with neuronal morphology and NF positive cells did not stain positively for glial fibrillary acidic protein. Approximately $5 \%$ of uninfected cells were
Table TI56 and neurofilament expression in retinal cell cultures following HSV-1 infection

\begin{tabular}{ccc}
\hline & \multicolumn{2}{c}{ Percentage ${ }^{\prime}$ of cells labelling with: } \\
\cline { 2 - 3 } & TI56 & Neurofilament \\
\hline $\begin{array}{c}\text { Retinal cultures } \\
\text { Uninfected }\end{array}$ & $5^{\star}$ & 24 \\
Infected \\
$6 \mathrm{hr}$ & $11^{\star}$ & 14 \\
$24 \mathrm{hr}$ & $33^{+}$ & 10 \\
$48 \mathrm{hr}$ & $35^{+}$ & 12 \\
Co-cultures & $1 \cdot 5^{\star}$ & 55 \\
Uninfected & $11^{\star}$ & Not available \\
Infected & $6 \mathrm{hr}$ & 35 \\
$24 \mathrm{hr}$ & $55^{+}$ & Not available \\
$48 \mathrm{hr}$ &
\end{tabular}

ॠWeak staining ${ }^{+}$strong staining.

'Figures show mean percentage of cells labelling based on five independent experiments in retinal (laminin coated) cultures and three independent experiments in co-cultures. In each case at least 150 cells per coverslip were counted. Results were not always obtained for every time point.

very weakly labelled with TI56. The fluorescence was perinuclear and cytoplasmic in distribution showing occasionally a granular pattern. There was no positive staining with normal rabbit serum or mouse ascitic fluid. Approximately $20 \%$ of uninfected exponentially growing BHK cells were $\mathrm{TI} 56^{+}$confirming our previous studies. ${ }^{46}$ The results are summarised in the table.

By six hours after infection with HSV, a cytopathic effect (cpe) was present in approximately $15-20 \%$ of cells. The cpe was less extensive in the co-cultures with Muller cells than in those on the laminin substrate. Low levels of HSV antigens were present in $30 \%$ of cells on the basis of immunofluorescent staining. The proportion of $\mathrm{NF}^{+}$cells in retinal cultures on the laminin substrate was reduced by $40 \%$. TI56 was weakly expressed in about $11 \%$ of cells, many of which had preserved neuronal morphology (fig 2). The distribution of fluorescence was diffuse cytoplasmic, perinuclear and also located on the plasma membrane. No positive staining with control sera could be seen in the infected cultures. In BHK cells, the timing and extent of the cpe and TI56 expression of infected cells were consistent with the results described previously. ${ }^{46}$

At 24 hours after infection a cpe was prominent in approximately $40 \%$ of cells but was again less marked in the preparations co-cultured

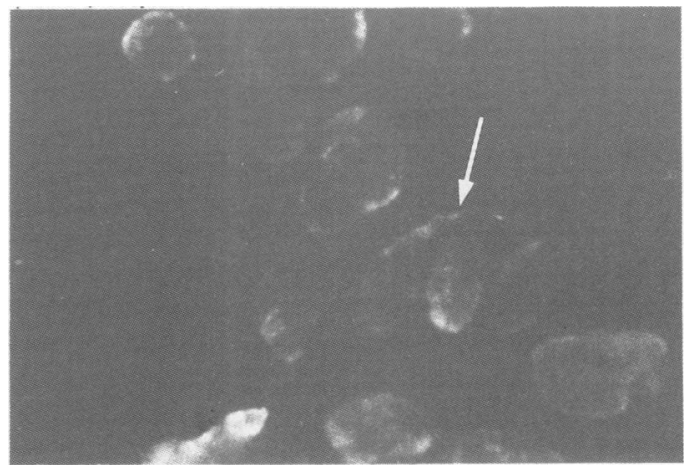

Figure 2 Immunofluorescence six hours after HSV infection stained with TI56 antibody. Weak labelling is seen in the plasma membrane and neurite (arrow) and cytoplasmic staining is seen in a cell at the bottom left of the field. Magnification $\times 1000$. 
Figure 3

Immunofluorescence 24

hours after $H S V$ infection stained with TI56 antibody. $A$ surface and cytoplasmic pattern of staining is seen, and a cytopathic effect is evidence as rounding up Magnification $\times 500$. and clumping of cells.

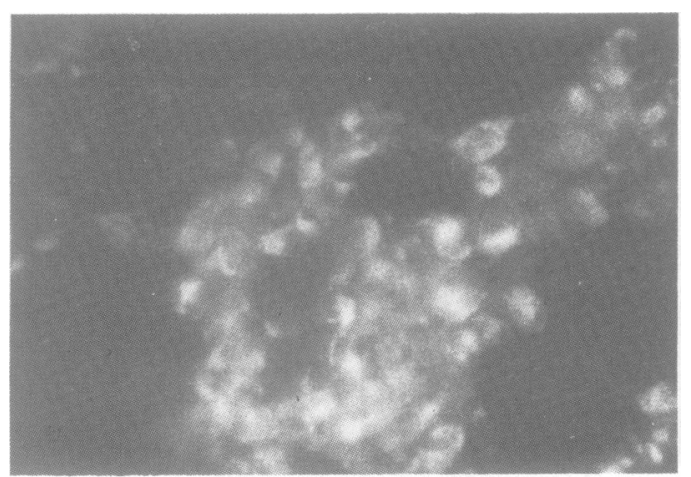

with Muller cells. Approximately $50 \%$ of cells were $\mathrm{HSV}^{+}$as determined by immunofluorescent staining. The neurites were also labelled with anti-HSV (fig 4). In the cultures infected at a MOI of $10 \mathrm{pfu} / \mathrm{cell}$ some cells had detached from the coverslips. The expression of NF was seen in only $10 \%$ of cells in laminin precoated cultures, but in the co-cultures $35 \%$ of cells were positive. The cells with neuronal morphology appeared to be greater in number than $\mathrm{NF}^{+}$cells. In double-labelling experiments, approximately $25 \%$ of $\mathrm{NF}^{+}$cells were also $\mathrm{HSV}^{+}$. There was strong labelling in approximately $35 \%$ of cells with TI56 antibody, there being cytoplasmic, perinuclear, nuclear and plasma membrane staining. The staining pattern with TI56 occasionally showed a characteristic honeycomb appearance (fig 3). Approximately $20 \%$ of the cells with neuronal processes were labelled with TI56. No positive staining was seen with mouse ascitic fluid or rabbit serum.

By 48 hours after the infection $80-90 \%$ of cells in neuronal cultures exhibited a cpe although some areas of co-cultured cells showed markedly less cpe $(45 \%)$. There was also a considerable loss of cells from some coverslips secondary to the extensive cpe. Approximately $12 \%$ of cells were labelled with antibody to NF. The co-cultured cells preserved relatively long neuronal processes while the cells on the laminin substrate possessed only short processes. Double-labelling experiments showed that approximately $70 \%$ of $\mathrm{NF}^{+}$cells were also $\mathrm{HSV}^{+}$, and $10-15 \%$ of $\mathrm{HSV}^{+}$cells were also $\mathrm{NF}^{+}$. TI56 was strongly detected in $35 \%$ of cells, but only a few TI56 positive cells had neuronal morphology. No staining was seen with control mouse ascitic fluid and rabbit serum.

Figure $4 \mathrm{HSV}$-specific immunofluorescence 24 hours after $H S V$ infection. Note the neurites are also labelled. Magnification $\times 850$.

\section{Discussion}

Cultures of mammalian retinal neurons of high purity have not previously been obtained. Substrate-attached laminin stimulates neurite outgrowth in retinal cultures ${ }^{120-22}$ and recently mammalian retinal neurons have been successfully co-cultured with retinal glial cells. ${ }^{23}{ }^{24} \mathrm{We}$ have recently reported laminin expression in cultured Muller cells and have conducted a quantitative comparative study of neonatal rat retinal neurons cultured on laminin-precoated coverslips and co-cultured with Muller cells from adult rabbits. ${ }^{11-14}$ Both the high proportion of $\mathrm{NF}^{+}$cells in the retinal cultures and the morphological appearance provide clear evidence that a substantial proportion of cells in these cultures were retinal neurons.

The 57K StrP was expressed at low levels in a small proportion of uninfected cells in these cultures. A similar observation has also been noted previously in other cell types. ${ }^{4618}$ This StrP is a cell-encoded protein which is constitutively expressed at low levels and upregulated after $\mathrm{HSV}$ infection.

The proportion of $\mathrm{HSV}^{+}$cells and cells with a cpe increased with time after infection. This implies that retinal neurons are capable of being infected with $\mathrm{HSV}-1$, a result that was confirmed unambiguously by double-labelling using antibodies to HSV and NF. Neuronal cells are relatively resistant to acute infection by HSV $-1 .{ }^{18}$ Judging by the timing of viral antigen expression, retinal neurons are similar in this respect to neurons from dorsal root ganglia (DRG) ${ }^{18}$ but the frequency of cpe in retinal neurons is no different from that in Muller cells. ${ }^{6}$ However, it should be pointed out that the neonatal DRG cells used in these previous studies were more mature than the retinal cells obtained from newborn animals, and are also surrounded by satellite cells so that a variety of factors may determine the observed differences between the two culture systems.

Interestingly, the events following HSV infection appeared to slow down in those cultures in which neurons were co-cultured with Muller cells, suggesting the neuronal-glial interaction may alter the susceptibility of retinal cells to HSV infection.

A 56K StrP was considerably upregulated with time after HSV infection. These findings were essentially consistent with previous studies using other cultured cells. ${ }^{4616}$ The staining pattern including nuclear localisation was also comparable to that seen in BHK cells, ${ }^{16}$ human dorsal root ganglia neurons ${ }^{4}$ and rabbit Muller cells. ${ }^{6}$ By contrast, the proportion of cells expressing NF decreased with time. There are several factors which should be taken into account in the interpretation of these phenomena. At 24 and 48 hours after infection, some cells became detached from the coverslips presumably secondary to the extensive cpe. These cells may have expressed NF. Further, NF expression may be downregulated as a consequence of viral infection. The combination of StrP induction and inhibition of normal protein synthesis appears to be a characteristic and common cellular response after heat shock, viral infection and treatment with toxic 
agents. ${ }^{12}$

Although the actual role of StrP is not known, it is generally believed that they are involved in cellular homeostasis. ${ }^{12}$ Kennedy et $a l^{4}$ suggested that StrP may provide an avenue by which host cell control may be exerted during HSV infection. The temperature elevation which produces StrP has been used to induce viral latency in cultured rabbit corneal cells in vitro. ${ }^{25}$ Thus, StrP could contribute to the regulation of HSV latency. Openshaw, using mice, provided evidence for HSV latency within retinal explants three months or more after corneal inoculation of the virus. ${ }^{26}$ Both a clinical case of $\mathrm{HSV}-1$ retinitis ${ }^{19}$ and an experimental model of $\mathrm{HSV}-1$ inoculation to the anterior chamber of the mouse ey $\mathrm{e}^{27}$ suggested that the virus could be transported via neural pathways involving the optic nerve to the central nervous system. Axonal transport of a $74 \mathrm{~K}$ StrP has been demonstrated ${ }^{7}$ and in the present study a $57 \mathrm{~K}$ StrP was also localised in neural processes. If StrP play a role in the regulation of both lytic and latent infections caused by HSV, this characteristic cellular response which has now been demonstrated in retinal neurons might make an important contribution to the pathogenesis of retinal diseases induced by the virus. It is clearly now technically possible to use cultured retinal neurons to investigate the molecular basis of viral pathogenesis in vitro.

We are grateful for the support of Professor J H Subak-Sharpe and the excellent technical assistance of Mrs F Jamieson. We thank Dr N B Lathangue, Dr R N Wood and Dr H S Marsden for their generous gifts to the study.

This study was supported by the Wellcome Trust and by the Medical Research Council.

1 Schlesinger MJ. Heat shock proteins: the search for functions. J Cell Biol 1986;103:321-5.

2 Schlesinger MJ, Ashburner M, Tissieres A. Heat shock from bacteria to man. (Cold Spring Harbor). New York: bacteria to man. (Cold

3 Cosgrove JW, Brown IR. Heat shock protein in mammalian brain and other organs after a physiologically relevant increase in body temperature induced by $D$-lysergic acid diethylamide. Proc Nat Acad Sci (USA) 1983;80:569-73.

4 Kennedy PGE, LaThangue NB, Chan WL, Clements GB.
Cultured human neuronal cells accumulate a heat shock protein during acute herpes simplex virus infection. Neurosci Lett 1985;61:321-6.

5 Barbe MF, Tytell $M$. Heat shock proteins may enhance retinal survival following light damage. Invest Ophthal Vis Sci (ARVO Abstract) 1987;28:141.

6 Wakakura M, Kennedy PGE, Foulds WS, Clements GB. Stress proteins accumulate in cultured retinal glial cells during herpes simplex virus infection. Exp Eye Res 1987;45:557-67.

7 Clark BD, Brown IR. Axonal transport of a heat shock protein in the rabbit visual system. Proc Nat Acad Sci (USA) 1985;82:1281-5.

8 Tytell M, Greeberg SG, Lasek RJ. Heat shock-like protein is transferred from glia to axon. Brain Res 1986;363:161-4.

9 Culbertson WW, Blumenkranz MS, Haines H, Gass JDM Mitchell KB, Norton EWD. The acute retinal necrosis. Part 2: Histopathology and etiology. Ophthal 1982; 89:1317-25

10 Minckler DS, McLean EB, Shaw CM, Hendrickson A. Herpesvirus hominis encephalitis and retinitis. Arch Ophthal 1976;94:89-95.

11 Wakakura M, Foulds WS. Immunocytochemical characteristics of Muller cells cultured from adult rabbit retina. Invest Ophthal Vis Sci 1988;29:892-900.

12 Wakakura M, Foulds WS. Laminin expressed by cultured Muller cells stimulates growth of retinal neurites. Exp Eye Res 1989;48:577-82.

13 Wakakura M, Foulds WS. Comparative ultrastructural study of rabbit Muller cells in vitro and in vivo. Eye 1989;2:664-9.

14 Wakakura M, Foulds WS. Response of cultured Muller cells to heat shock and intermediate filament proteins in response to temperature elevation. Exp Eye Res 1989,48:337-50.

15 Burke JM, Foster SJ. Culture of adult rabbit retinal glial cells; methods and cellular origin of explant outgrowth. Current Eye Res 1984;3:1169-78.

16 LaThangue NB, Shriver K, Dawson C, Chan WL. Herpes simplex virus infection causes the accumulation of a heat shock protein. EMBO J 1984;3:267-77.

17 Wood JN, Anderton B. Monoclonal antibodies to mammalian neurofilaments. Biosc Rep 1981;1:263-8.

18 Kennedy PGE, Clements GB, Brown SM. Differential susceptibility of human neural cell types in culture to infection with herpes simplex virus. Brain 1983;106: 101-19.

19 Johnson BL, Wisotzkey HM. Neuroretinitis associated with herpes simplex encephalitis in an adult. Am J Ophthal 1977;83:481-9.

20 Adler R, Jerdan J, Hewitt AT. Responses of cultured neural retinal cells to substratum-bound laminin and other extracellular matrix molecules. Develop Biol 1985; 112:100-14.

21 Hall DH, Neugebauer KM, Reichardt LF. Embryonic neural retinal cell response to extracellular matrix proteins: Developmental changes and effects of the cell stratum attachment antibody (CSAT). J Cell Biol 1987;104:623-4.

22 Smalheiser NR, Crain SM, Reid LM. Laminin as a substrate for retinal axons in vitro. Develop Brain Res 1981;12: 136-40.

23 Oka MS, Frederick JM. Landers RA, Bridges CDB. Adult human retinal cells in culture. Identification of cell types and expression of differentiated properties. Exp Cell Res 1985;159:127-40.

24 Raju TR, Bennett MR. Retinal ganglion cell survival requirements: A major but transient dependence of Muller glia during development. Brain Res 1986; Muller glia

25 Cook SD, Brown SM. Herpes simplex virus type 1 persistence and latency in cultured rabbit corneal epithelial cells, keratocytes and endothelial cells. Brit J Ophthalmol 1986;70:642-50.

26 Openshaw HR. Latency of herpes simplex virus in ocular tissue of mice. Infection and Immunity 1983;39:960-9.

27 Atherton SS, Streilein JW. Two waves of virus following anterior chamber inoculation. Invest Ophthal Vis Sci 1987;28:571-9. 